\section{Acceptance of cataract surgery in a cohort of Tanzanians with operable cataract}

E Chibuga1', P Massae², R Geneau², M Mahande², $S$ Lewallen $^{2}$ and $\mathrm{P}$ Courtright ${ }^{2}$
${ }^{1}$ Kilimanjaro Christian Medical College, Moshi, Tanzania

${ }^{2}$ Kilimanjaro Centre for Community Ophthalmology, Moshi, Tanzania

Correspondence: $\mathrm{P}$ Courtright, Kilimanjaro Centre for Community Ophthalmology, Tumaini University/KCMC, PO Box 2254, Moshi, Tanzania Tel: 255-27-2753547; Fax: 255-27-2753598. E-mail: pcourtright@ kcco.net

Received: 8 July 2006 Accepted in revised form: 28 December 2006 Published online: 2 February 2007

\begin{abstract}
Background In spite of recent increases in the number of surgeries carried out within some hospitals and programmes in sub-Saharan Africa, there are indications that the acceptance of cataract surgery remains quite low. Methods We conducted a population-based prospective (cohort) study of cataract patients from 12 villages in Hai district of Kilimanjaro region, Tanzania. Those identified with operable cataract were informed of the regular community programmes (within $5 \mathrm{~km}$ ) in place providing transportation and high-quality surgery. At years 1 and 2 after the survey, we traced the patients to determine uptake of cataract surgery.

Results Among patients eligible for surgery (128), 31 could not be followed up after 1 year due to deaths, moving, and refusal. Among the remaining patients, 18 accepted surgery in the first year and four accepted in the second year. Among these 22 patients, only five were blind or with severe visual impairment. The most elderly were those least likely to accept surgery. Discussion Even with bridging strategies in place to make cataract surgery accessible and affordable, the uptake of cataract surgery remains low. Strategies aimed to identifying and referring all patients recognizing vision loss as a personal disability rather than using predefined vision cutoffs will likely be most successful in reducing the burden of vision loss due to cataract.

Eye (2008) 22, 830-833; doi:10.1038/sj.eye.6702736; published online 2 February 2007
\end{abstract}

Keywords: cataract; cataract surgery; Tanzania

\section{Introduction}

Much effort is being directed at developing high-quality cataract surgical services in Africa and VISION 2020 suggests that the cataract surgical rate (CSR) target should be 2000 surgeries per million population per year. Although some programmes have documented CSR of 1000-2000, the average CSRs in Africa are estimated to be around $300 .{ }^{1}$ In Kilimanjaro Region, we saw the CSR rise from around 400 in 2000 to 1165 in 2004 after we implemented a community programme designed to bridge the gap between community and hospital services. The Kilimanjaro CSR remains lower than the target and we required information on uptake from a population-based perspective. We sought to determine the uptake of cataract surgery after 2 years among a cohort of cataract patients who were identified with operable cataract in a population-based survey in 2002.

\section{Methods}

In September 2002, we conducted a populationbased prospective (cohort) study of cataract patients from 12 villages in Hai district of Kilimanjaro region, Tanzania. The lowland villages were selected based upon their proximity to a defined catchment area to be served by the new bridging strategy, implemented in October 2002. The strategy has been described elsewhere. ${ }^{2}$ Briefly, it involves regular team visits to fixed sites in the community where patients receive free examination and treatment; cataract patients are offered transportation that day to the hospital for surgery the following day. Before a visit, promotion in the community and through radio indicates the date, time, and place of the visit in addition to the cost of surgery (a subsidized price of $\$ 14$ covers all transport, surgery, and medicines). Patients too poor to pay are requested to obtain an exemption letter from community leaders. 
For the survey, in each of the selected villages, all households were visited and people over the age of 40 were enumerated and invited to come to a central site in the village the next week for examination. Enumerated people who failed to attend for examination were traced on the examination days and assisted to the examination site or examined in their homes. Additional visits were made to find patients who were away at the time of the examinations.

The survey team consisted of an ophthalmologist, nurse, and an interviewer. They were trained and the methods were pilot-tested. Examination included visual acuity (Snellen's E), pinhole acuity in eyes less than 6/18. Pupils were checked and the anterior segment was examined with torch and loupes. Patients with a vision $<6 / 18$ (and no corneal disease obstructing visualization of the pupil) were dilated and direct ophthalmoscopy was carried out. For the purpose of our study, a patient with an operable cataract was defined as lens opacification detected by direct ophthalmoscopy in a dilated eye, no evidence of macular pathology (if visible) and presenting vision less than or equal to $6 / 24$. Patients with one or both eyes meeting this definition were counselled about cataract and advised that they could attend a nearby (less than $5 \mathrm{~km}$ ) site, where transport would be provided to hospital or to come directly to hospital for cataract surgery.

In six villages (randomly selected), the village leaders were visited and informed of the programme and requested to assist their community members who had visual difficulties. In the other six villages, one schoolteacher and the headmaster from the primary school were educated about cataract and trichiasis and asked to assist community members who had visual difficulties to accept surgery.

Over the next 2 years, five to eight outreach visits were made to these villages. All were advertised ahead of time. In addition, in-depth interviews were undertaken with half of the study population between October 2002 and 2004 (findings published previously ${ }^{3}$ ). In September 2003 and January 2005, all enrolees were traced to their residence and re-examined. Risk ratios and 95\% confidence intervals were used to assess factors associated with acceptance. Ethical clearance from the Kilimanjaro Christian Medical College Ethics Committee was obtained and informed (oral) consent was obtained from potential study subjects before enrolment.

\section{Results}

Among the 14514 residents of the 12 villages, there were 1586 people over the age of 40 years; 1331 (84\%) were examined. There were eight people who had had surgery for cataract among the 136 people identified with operable cataract plus those who had surgery, giving a cataract surgical coverage of 5.9\%. For the purpose of this study, 128 patients were diagnosed with operable cataract and enrolled. At follow-up in 2003, we examined 97 of these patients. Thirty-one could not be examined; nine died, five refused, and 17 had moved. Among the 97 patients, only $18(18.6 \%)$ had accepted surgery in the previous year. In 2004, we sought to find the 79 patients who had not had surgery yet. In the second year, seven had died and only four had undergone cataract surgery. Thus, the 2 years cumulative uptake was $22 / 90$ or $24.4 \%$.

All patients reported being aware of surgery and the local site where they could get transport to hospital for surgery. After 1 year, $23.8 \%$ of those who were blind or with severe visual impairment accepted surgery, whereas $21.2 \%$ of patients who had 'normal vision' (vision reducing cataract in one eye and vision of $6 / 18$ or better in the second eye) had accepted surgery. Of the 22 people who eventually accepted surgery, five (22.7\%) were blind and $17(77.3 \%)$ had normal vision or visual impairment at baseline. Those least likely to accept were the most elderly (Table 1). A search of the KCMC Hospital surgical database revealed only one additional patient having surgery between January 2005 and January 2006.

\section{Discussion}

Low acceptance of cataract surgery has been reported in Africa. ${ }^{4-8}$ Even among patients who travel to 'outreach clinics,' the proportion with operable cataract who accept surgery varies from 51 to $93 \%$ (authors unpublished data from five programmes in eastern and southern Africa). However, it seems that a large proportion never get as far as the outreach site. In this population-based study, with a programme in place to make surgery accessible and affordable less than $25 \%$ of people accepted surgery and those most likely to accept were not the blind or visually impaired. There are several possible implications of our findings.

First, programmes using visual acuity cutoffs (blind or severe visual impairment) to determine who should get cataract surgery may exclude the majority of people willing to accept surgery. The tendency for health workers, or even ophthalmologists to deny surgery because the cataract is 'not mature,' and the potential for this practice to leave patients blind for far longer than necessary, has been reported previously. ${ }^{9}$ On the other hand, in settings where there are no A scans nor postoperative spectacles available it is not clear how often eyes with $6 / 24,6 / 36$, or even $6 / 60$ cataracts are actually improved by surgery. There are insufficient data to assess this because routine systems for monitoring surgical outcomes in Africa remain generally unrealized.

Generally, however, we view the tendency for more patients who are not yet blind to accept surgery as an 
Table 1 Characteristics of the study population

\begin{tabular}{|c|c|c|c|c|}
\hline Parameter & $\begin{array}{c}\text { Acceptors within } \\
\text { Year } 1\end{array}$ & $\begin{array}{c}\text { Cumulative } \\
\text { acceptors by the } \\
\text { end of year } 2\end{array}$ & $\begin{array}{l}\text { Non-acceptors by } \\
\text { the end of year } 2\end{array}$ & $\begin{array}{l}\text { Risk ratio for } \\
\text { acceptance by the } \\
\text { end of year } 2 \\
(95 \% \mathrm{CI})\end{array}$ \\
\hline \multicolumn{5}{|l|}{ Age group } \\
\hline$<60$ years & $1(16.7)$ & $1(16.7)$ & $5(83.3)$ & 1.0 \\
\hline $60-69$ years & 4 (14.3) & $7(25.0)$ & $21(75.0)$ & $1.50(0.22-10.04)$ \\
\hline $70-79$ years & $10(29.4)$ & $11(32.4)$ & $23(67.6)$ & $1.94(0.30-12.40)$ \\
\hline $80+$ years & 3 (10.3) & 3 (10.3) & $29(89.7)$ & $0.56(0.07-4.54)$ \\
\hline \multicolumn{5}{|l|}{ Sex } \\
\hline Male & $9(16.4)$ & $12(21.8)$ & $43(78.2)$ & $0.92(0.44-1.91)$ \\
\hline Female & $9(21.4)$ & $10(23.8)$ & $32(76.2)$ & 1.0 \\
\hline \multicolumn{5}{|c|}{ Vision (best eye) at baseline in $2002^{\mathrm{a}}$} \\
\hline Blind or SVI & $5(23.8)$ & $5(23.8)$ & $8(76.1)$ & 1.0 \\
\hline VI & $6(14.0)$ & $8(18.6)$ & $35(81.4)$ & $0.78(0.29-2.10)$ \\
\hline Normal & $7(21.2)$ & $9(27.3)$ & $24(72.7)$ & $1.15(0.44-2.95)$ \\
\hline \multicolumn{5}{|l|}{ Intervention } \\
\hline Schoolteachers & $7(16.7)$ & $10(23.8)$ & $32(76.2)$ & $1.09(0.52-2.28)$ \\
\hline Village leaders & $11(20.0)$ & $12(21.8)$ & $43(78.2)$ & 1.0 \\
\hline
\end{tabular}

Abbreviation: $\mathrm{CI}$, confidence interval.

${ }^{a}$ Blind $=<3 / 60$ in the best eye, presenting, SVI (severe visual impairment) $=5 / 60-3 / 60$, VI (visual impairment) $=6 / 24-6 / 60$, normal $=6 / 18$ or better in the best eye, presenting.

encouraging trend. Good-quality surgery can prevent cataract blindness. Given the social dynamics of rural communities in places like Kilimanjaro Region the younger, non-dependent cataract patient may be more likely to become a promoter for eye care in his or her community. An informed and motivated younger population may contribute to increase acceptance in the next 10-20 years.

Another implication is that there is much we do not understand about acceptance of cataract surgery. An assumption that all cataract blind people are eager to accept surgery if only they can access it appears to be unwarranted. Indeed, some of the factors determining acceptance of surgery which operate within this population have already been described as involving complex family and social processes unfolding over several months or sometimes years. ${ }^{3}$ Counselling efforts need to be directed at family members as well as the patients themselves but this is difficult, as family members increasingly do not live in the village.

Community social structures are highly variable and may be weak; neither village leaders nor schoolteachers seemed particularly influential in getting patients to surgery in our setting.

The interpretation of our findings is limited by the small number of cataract patients we detected in the baseline study. We anticipated approximately 80 blind and an additional 160 visually impaired from cataract study subjects, given current estimates of blindness at $1 \%$ of the population. Instead, we found only 12 blind and 52 visually impaired from cataract. This is similar to findings from a recent survey in Kenya (W. Mathenge, unpublished data presented at OSEA, Kampala, Uganda, 2005) and Tanzania. ${ }^{10}$ The free movement of many older people, as evidenced by our inability to trace 17 people at follow-up, also limits interpretation.

Although multiple studies have reported barriers to use of cataract surgical services in Africa, further qualitative research is needed and much remains to be carried out to turn these findings into operational programmes. Preventing blindness through increasing uptake of cataract surgery in rural Africa will require multiple strategies and evidence of effectiveness of strategies is needed. Economic and social factors facilitating early acceptance of surgery (before blindness) offers much hope for the future and capitalizing on this potential is critical.

\section{Acknowledgements}

The survey team leaders were Hemed Kilima, Judith Mwende, and Martha Temba; we are grateful for their efforts and those of entire team. This work was supported by a grant from the World Health Organization Gender, Women and Health Unit. Additional support was provided by the Seva 
Foundation and Seva Canada. We are grateful for their support as well as for the cooperation of the residents of Hai district of Kilimanjaro Region.

\section{References}

1 Lewallen S, Courtright P. Blindness in Africa: present situation and future needs. Br J Ophthalmol 2001; 85: 897-903.

2 Lewallen S, Roberts H, Hall A, Onyange R, Temba M, Banzi $\mathrm{J}$ et al. Increasing cataract surgery to meet Vision 2020 targets; experience from two rural programmes in east Africa. Br J Ophthalmol 2005; 89: 1237-1240.

3 Geneau R, Lewallen S, Bronsard A, Paul I, Courtright P. The social and family dynamics behind the uptake of cataract surgery: findings from Kilimanjaro region, Tanzania. $\mathrm{Br} J$ Ophthalmol 2005; 89: 1399-1402.

4 Bucher PJM, Ijsselmuiden CB. Prevalence and causes of blindness in the northern Transvaal. Br J Ophthalmol 1988; 72: 721-726.
5 Eloff J, Foster A. Cataract surgical coverage: results from a population-based survey at Nkoma, Malawi. Ophthalmic Epidemiol 2000; 7: 219-221.

6 Melese M, Alemayehu W, Friedlander E, Courtright P. Indirect costs associated with accessing eye care services as a barrier to service use in Ethiopia. Trop Med Int Health 2004; 9: 426-431.

7 Courtright P, Metcalfe N, Hoechsmann A, Chirambo M, Lewallen S, Barrows J, et al, the Chikwawa Survey Team. Cataract surgical coverage and outcome of cataract surgery in a rural district in Malawi. Canad J Ophthalmol 2004; 39: 25-30.

8 Rotchford AP, Rotchford KM, Mthethwa LP, Johnson GJ Reasons for poor cataract surgery uptake - a qualitative study in rural South Africa. Trop Med Int Health 2002; 7: 288-292.

9 Vaidyanathan K, Limburg H, Foster A, Pandey RM. Changing trends in barriers to cataract surgery in India. Bull World Health Organ 1999; 77: 104-109.

10 Burke AG, Patel I, Munoz B, Kayongoya A, Mchiwa W, Schwarzwalder AW et al. Population-based study of presbyopia in rural Tanzania. Ophthalmology 2006; 113 723-727. 